\title{
Study on Cervical Spine Injuries in Vehicle Side Impact
}

\author{
Shu-Wen Zhou ${ }^{1}$, Li-Xin Guo ${ }^{*}, 1$, Si-Qi Zhang ${ }^{1,2}$ and Chuan-Yin Tang ${ }^{1}$ \\ ${ }^{I}$ School of Mechanical Engineering and Automation, Northeastern University, Shenyang 110004, China \\ ${ }^{2}$ Traffic and Mechanical Engineering School, Shenyang Jianzhu University, Shenyang 110168, China
}

\begin{abstract}
This paper presents the development and study of a three-dimensional multi-body model of the 50th percentile male human and discretized neck for the study of cervical spine injuries in vehicle side impact. The neck is composed of cervical spine vertebrae, intervertebral discs, ligaments, and muscles. Following motor crash evaluations, an impactor with a deformable front end representing the front of a car was propelled straight ahead into the sides of the vehicles being assessed. A EuroSID-2 adult male dummy was seated on a sled, restrained using safety belt, and lateral velocity measured from side impact was applied to simulate cervical spine injuries. The results show that the methods used in this paper have the potential to provide a costeffective and versatile platform to examine local loadings on the cervical spine and soft tissues, including the kinetics and the kinematics of the cervical spine and its components, as well as the mechanical response of the intervertebral discs under other complex dynamic loading environment.
\end{abstract}

Keywords: Cervical spine, multibody model, side impact, biomechanics, soft tissues.

\section{INTRODUCTION}

Side impact, commonly known as T-bone collisions, is where the side of one vehicle is hit by the front or rear of another vehicle or a fixed object. An occupant on the struck side of a vehicle may sustain far more severe injuries than an otherwise similar front or rear collision crash. Serious cervical spine injury will result in a huge economic burden of medical and insurance costs and loss of work force. If misdiagnosed or untreated, soft tissue injuries in cervical spine may lead to clinical instability and chronic pain.

Neck sprains and strains are the most frequently reported injuries in US insurance claims. In 2007, an estimated 66 percent of all insurance claimants under bodily injury liability coverage and 57 percent under personal injury protection coverage - two important insurance injury coverages - reported minor neck injuries. For 43 and 34 percent of bodily injury liability and personal injury protection claimants, respectively, neck sprains or strains were the most serious injuries reported. The cost of the claims in which neck pain was the most serious injury was about $\$ 8.8$ billion, representing approximately 25 percent of the total dollars paid for all crash injuries combined.

What happens to the soft tissue in an accident? The answer to that is even in a slow speed collision, the forces applied to bones, muscles, and joints of the body are clearly capable of inflicting significant injury. Almost all joints are pulled and twisted. Why? Because the body of the occupant is first accelerated in his seat due to the side impact, the head remains static. This inflicts tremendous force on the neck. Then, just as the neck is stretched to (or even beyond) its normal limits, the head starts its lateral motion, the neck

*Address correspondence to this author at the School of Mechanical Engineering and Automation, Northeastern University, Shenyang 110004, China; Tel: +8624-83691095; Fax: +8624-83691095;

E-mail:1xguo@mail.neu.edu.cn snaps back. When this takes place the head has accelerated up to five times the G-force of the impact - and then back. Muscles and ligaments can be stretched beyond their breaking strength. Discs can be damaged. Nerve roots or the spinal cord can be injured permanently [1].

Therefore, the cervical spine receives utmost attention in bioengineering discipline, not only to investigate the headand-neck to determine the biomechanical limits of its components for a better evaluation of the injury risk, but also to have an insight for the common injuries it is subjected to [2-7].

Injury mechanisms of the cervical spine soft tissues during motor vehicle collisions remain elusive [3-5]. There are few biomechanical studies documenting injuries to the cervical spine ligaments due to flexion-type loading, the most likely injury mechanism during frontal impact [4]. Typically two methods, Multibody Dynamics (MBD) [6-13] and Finite Element Methods (FEM) [14-22] are being using widely to study human spine and soft tissues mechanisms in order to have a better understanding of its kinetics, kinematics, and clinical aspects.

Some literatures investigated chest, pelvis and neck injuries, mechanisms, tolerances, and comparison with impact dummies using postmortem human subjects (PMHS) [2326]. Some literatures studied cervical spine injuries based on different anthropometric measurements on human volunteer test series [27, 28]. As is well known, it is impossible to carry out experiments on living volunteers to such a degree that injuries are produced. Therefore there has been great emphasis on computational simulation [29-39]. FE models need a great deal of computational power, but can provide detailed information about tissue deformations and injury prediction. Multi-body models can also include many anatomical details while being computationally efficient. This makes them suitable for parameter variation and optimization analyses [3-7]. 
Therefore, in this study we performed simulation to cervical spine injuries in motor vehicle collisions, with risk analysis when they are involved in side impact collisions. The side impact test is carried out by firing a deformable cart at $53 \mathrm{~km} / \mathrm{h}$ into the driver's side of a stationary car as shown in Fig. (1). Under these circumstances, the most frequently seriously injured part of the body is the driver's head, which can obtain substantial safety from the introduction of side impact airbags. So in this paper, the cervical spine injuries are our main concern. The impact problem of adult male dummy in driver seat was analyzed.

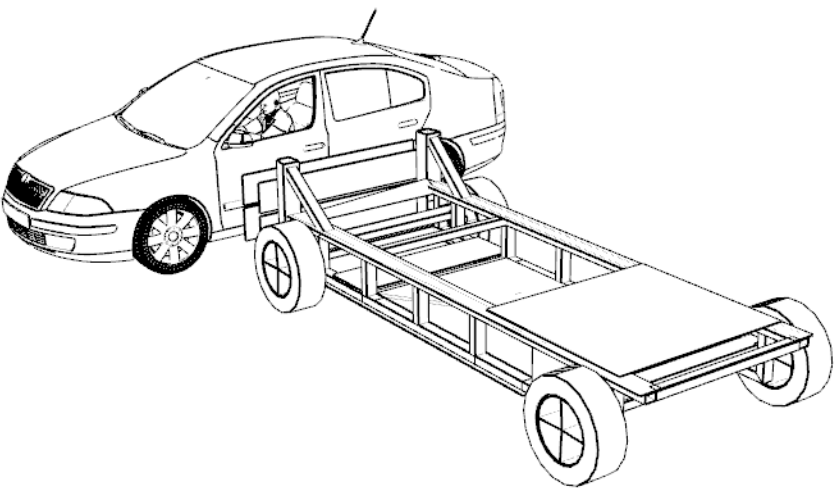

Fig. (1). Motor vehicle side crash sketch.

\section{CERVICAL SPINE ANATOMY}

The cervical spine consists of the first seven vertebrae running from the base of the skull to the chest. Sandwiched in between each of these vertebrae is a disc that is made of a gel-like material (the nucleus pulposus) enclosed within a more rigid covering, the annulus fibrosis. These discs act to cushion the vertebrae and absorb shock. The cervical spine anatomy is shown in Fig. (2).

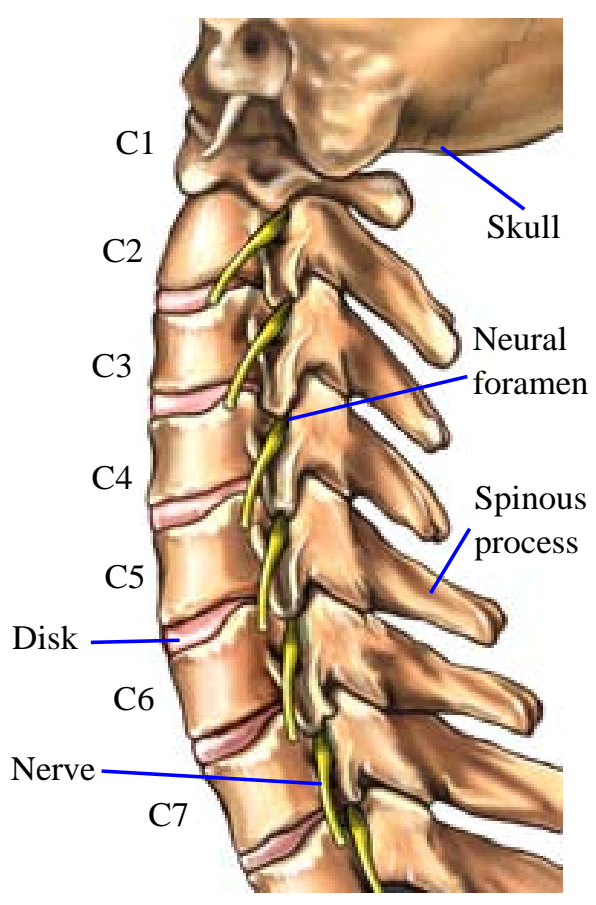

Fig. (2). Cervical spine anatomy.
The cervical spine has a backward "C" shape (lordotic curve) and is much more mobile than either of the thoracic or lumbar regions of the spine. Unlike the other regions of the spine, the cervical spine has special openings in each vertebrae for the arteries that carry blood to the brain.

\section{C1-C7 (Cervical Vertebrae)}

$\mathrm{C} 1$ through $\mathrm{C} 7$ are the symbols for the cervical (neck) vertebrae, the upper 7 vertebrae in the spinal column (the vertebral column). $\mathrm{C} 1$ is called the atlas. It supports the head and is named for the Greek god Atlas who was condemned to support the earth and its heavens on his shoulders. (Because the god Atlas often adorned maps, a compilation of maps came to be known as an atlas). $\mathrm{C} 2$ is called the axis because the atlas rotates about the odontoid process of $\mathrm{C} 2$. The joint between the atlas and axis is a pivot that allows the head to turn. C1 and C2 have special bony structures for supporting the movement of the skull.

Cervical vertebrae 3-7 are more typical. Although the general structures of the cervical spine are similar to the bony structures of the lower spine, there are key differences. The typical cervical vertebrae (C3-C7) are smaller than the vertebrae in the thoracic or lumbar areas. The disc material between the bones is about half as thick. Also, the cervical vertebrae have more of a rectangular shape in the body of the bone. There are two lips on the superior surface of the body of the cervical vertebrae. These lips interlock with the vertebrae above it. The cervical vertebrae are designed to allow more range of motion than the thoracic or lumbar areas, but also provide good stability in the neck region. The spinous processes project posteriorly, the longest of which is C7. C7 is sometimes called the prominent vertebra because of the length of its spinous process (the projection off the back of the vertebral body). Side collision survivors who experience chronic pain often sustain injuries that are undetectable radiographically.

A strain refers to an injury to a muscle, occurring when a muscle-tendon unit is stretched or overloaded. Cervical muscles that are commonly strained include the sternocleidomastoid (SCM), the trapezius, the rhomboids, the erector spinae, the scalenes, and the levator scapulae.

A sprain refers to a ligamentous injury, and the diagnosis of cervical sprain implies that the ligamentous and capsular structures connecting the cervical facet joints and vertebrae have been damaged. Practically, a cervical sprain may be difficult to differentiate from a strain, and the two injuries often occur simultaneously. Pain referred to the muscle can arise from any source that is modulated by the dorsal rami.

The cervical spine or the neck is usually subjected to several forms of injuries that are not seen in the thoracolumbar spine. Injuries to the upper cervical spine, particularly at the atlanto-occipital joint, are considered to be more serious and life-threatening than those at the lower level. The atlanto-occipital joint can be dislocated either by an axial torsional load or a shear force applied in the anteroposterior direction, or vice versa. A large compression force can cause the arches of $\mathrm{C} 1$ to fracture, breaking it up into two or four sections. The odontoid process of $\mathrm{C} 2$ is also a vulnerable area. Extreme flexion of the neck is a common cause of odontoid fractures, and a large percentage of these injuries 
are related to motor vehicle collisions. Some survivors will suffer acute strains and sprains of the musculature of the neck, as well as soft-tissue contusions.

\section{SIDE IMPACT SIMULATION}

Since 1997 the federal New Car Assessment Program, which compares crashworthiness among new passenger vehicles, has included side impacts. In these tests, an impactor with a deformable front end representing the front of a car is used to strike the sides of the vehicles being assessed. This moving deformable barrier was developed in the early 1980s, when cars represented most of the vehicles on the road. The height of the barrier's front end is below the heads of the dummies that measure injury risks in the sidestruck vehicles. Injuries commonly associated with this type of impact include head trauma, maxillofacial injury, spine fracture, thoracic injury, aortic transection, solid organ injury, hollow viscus perforation, and fractures of the femur, knee, and acetabulum.

When a passenger car is hit on the side by another vehicle, the crumple zones of the striking vehicle (the simulation reproduces the situation with a deformable cart attached of aluminum honey comb, the impact absorption material, to all impact areas) will absorb some of the kinetic energy of the collision. The passenger compartment which is inherently rigid and resistant to large deformation is designed to protect the occupants. The car begins accelerating as soon as the crumple zone of the striking vehicle starts crumpling, extending the acceleration over a few extra tenths of a second.

In this paper, a side impact model was built with Finite Element Methods, i.e. explicit, 3-D, dynamic FE computer codes were used to simulate side impact. The lateral velocity of the vehicle side panel can be measured through the side impact simulation and will be used as the initial condition of the analysis on the cervical spine injuries. Fig. (3) is the 90degree side impact test simulation under FMVSS 214 requirements. The vehicle was hit by an impactor with a deformable front end representing the front of a car propelled

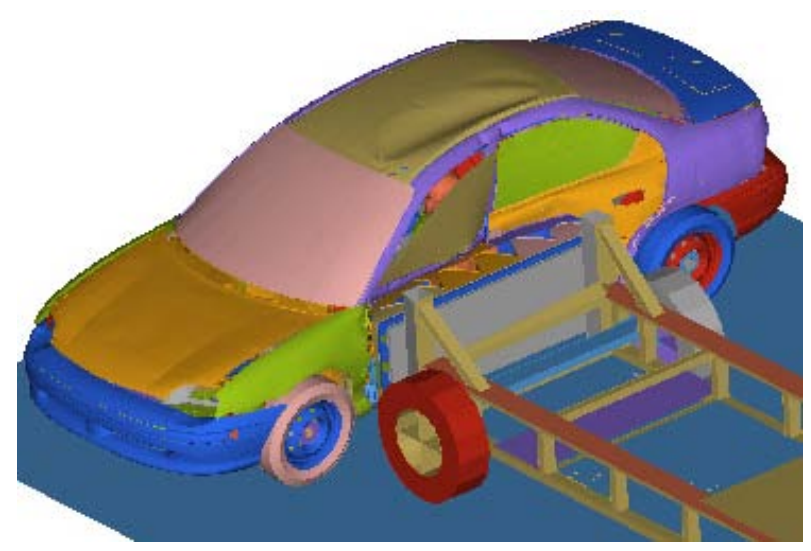

Fig. (3). Side impact simulation.

at a speed of 53 kilometers per hour $(\mathrm{km} / \mathrm{h})$. From the figure, less deformation can be seen on the motor side panel because of the inherently rigid passenger compartment comparing to the deformation of the impactor. Because of the buffer function of the aluminum honey comb of the moving deformable barrier, the impact on the test vehicle was decreased. Fig. (4) is the lateral velocity of left door measured in the side impact simulation, and will be used in the neck injuries simulation.

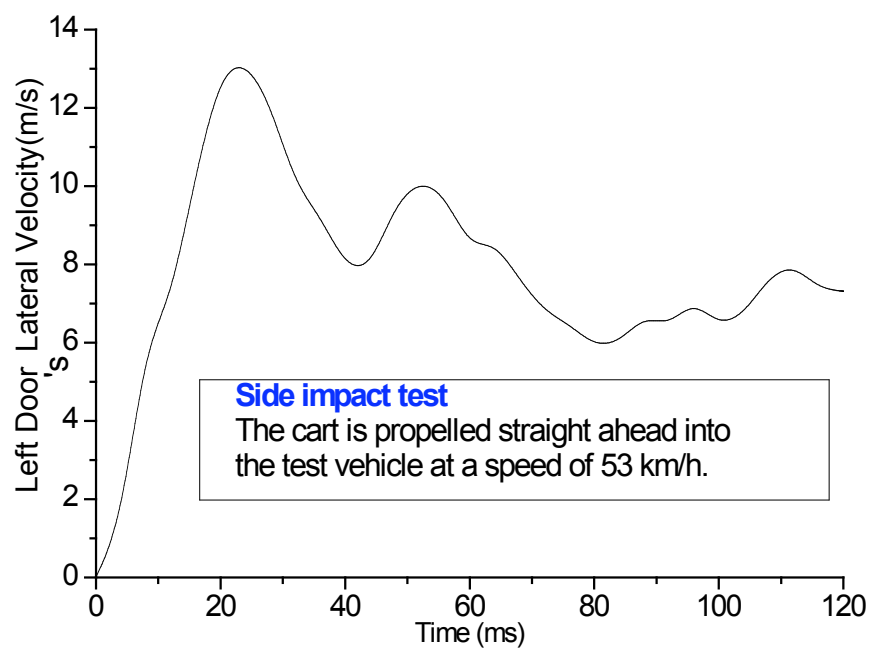

Fig. (4). Left door's lateral velocity.

In this paper, the body of the occupant is first accelerated in his seat due to the side impact, the head remains static. This inflicts tremendous force on the neck. Then, just as the neck is stretched to (or even beyond) its normal limits, the head starts its lateral motion, the neck snaps back.

\section{DRIVER MODEL CONSTRUCTION}

The aim of our study was to evaluate the muscle cervical spine load of human in motor vehicle collisions, for this purpose, A EuroSID-2 adult male dummy seated on a sled, restrained using safety belt, was built for a vehicle collision simulation.

The LifeMOD ${ }^{\mathrm{TM}}$ Biomechanics Modeler, from Biomechanics Research Group, Inc. is a plug-in module to the ADAMS physics engine. It allows for full functionality of ADAMS/View during the creation of human models. Since human models are built entirely within ADAMS/View, the human models may be combined with any type of physical environment or system for full dynamic interaction. The dummy of EuroSID-2 in this paper was designed based on biomechanics modeler commercially software.

The simulation dummy allows designers and engineers to test and evaluate product performance and characteristics while interacting with the validated 'virtual' model of a human body. Thousands of design iterations can be assessed for user comfort, safety, and fatigue - without expensive physical prototypes or crash-test dummies.

An anthropometric database is used to build the model body segments configurations; this database will relate the data of age, height, weight and sex (user defined) with the size of the several ellipsoids that bring together model parts. The values of joints stiffness and damping of the simulation dummy were set according to the parameters of EuroSID-2 dummy developed in Europe. The driver model was built with the following main parameters. 
- Age- 288 months

- Sex-Male

- Height- $178 \mathrm{~cm}$

- Weight- $72 \mathrm{~kg}$

All joints (Scapular, Shoulder, Elbow and Wrist) are passive joints with nominal stiffness. Fig. (5) is the driver model built with EuroSID-2 dummy parameters, seated on a sled and restrained using safety belt.

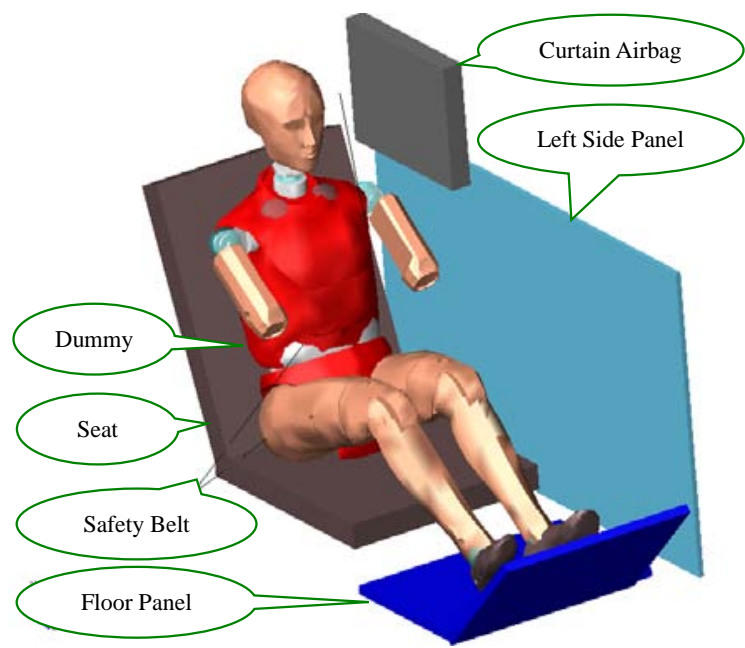

Fig. (5). Driver model construction.

In this paper, the single base segment of the neck is discretized into $\mathrm{C} 1-\mathrm{C} 7$ vertebrae elements. In addition to the individual parts, bushing forces representing disk compression and shear forces are automatically generated between the segments. Fig. (6) is the discretized neck. The model is stabilized with a set of ligament forces for the interspinous, flaval, anterior longitudinal and capsule, as shown in Fig. (6).

Muscle force sets representing the trapezius, semispinalis capitis, semispinalis cervicis, longus colli and the sternocleidomastoid are created on the model. The Hill-Formulation muscle model is used to model the muscle dynamics. Tissue sliding elements are created for each muscle to permit the interaction between the tissue and bone.

The Hill muscle formulas combine the A(t) curve and the physiological characteristics of the Hill-based muscles, which operate on the traditional combination of active contractile elements (CE) and parallel passive elements (PE) with force-length and force-velocity contraints.

$F=\left(F_{\mathrm{CE}}+F_{\mathrm{PE}}\right) \cdot T$

Equation 1 shows the formula used to place the strengthconditioning limits on Hill muscles where FCE can be found using the formula shown in Equation 2.

$F_{\mathrm{CE}}=\mathrm{A}(t) \cdot F_{\text {max }} \cdot \mathrm{F}_{\mathrm{H}}\left(V_{\mathrm{r}}\right) \cdot \mathrm{F}_{\mathrm{L}}\left(L_{\mathrm{r}}\right)$

Where:

$\mathrm{A}(\mathrm{t})=$ activation state (normalized between 0 and 1)

Fmax $=$ product of the physiological cross sectional area and maximum isometric muscle stress ( $\sigma \max )$
$\mathrm{FH}=$ the normalized active force-velocity relation (Hillcurve)

$\mathrm{FL}=$ the normalized active force-length relation

$\mathrm{Vr}=$ dimensionless lengthening velocity

$\mathrm{Lr}=$ dimensionless muscle length

$\mathrm{T}=$ muscle force output filter value between 0 and 2

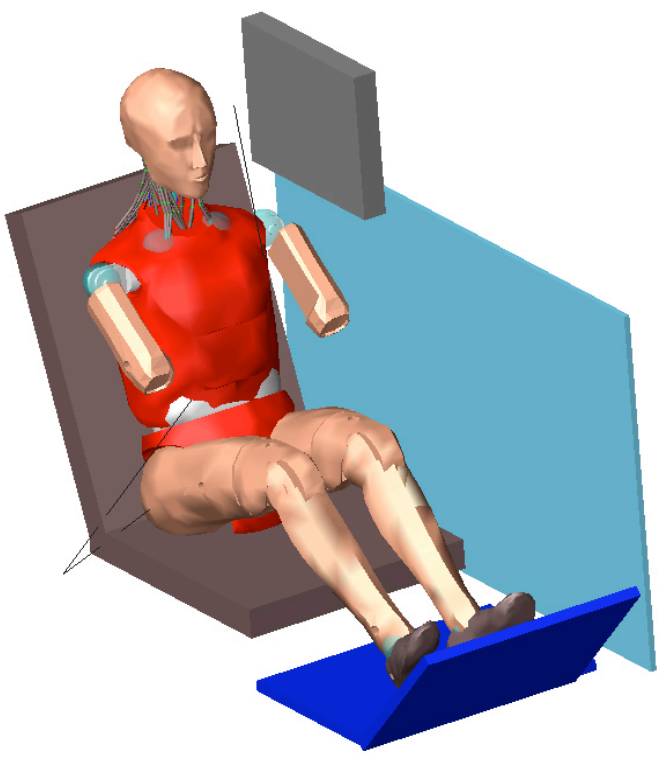

Fig. (6). Discretized neck.

A translational joint is used between the side panel and ground to provide a translational acceleration profile to the model representing a side impact. And the translational joint is driven with a translational joint motion using a velocity spline created from two dimensions velocity data according to Fig. (4). So the side panel can move as being hit by the moving deformable barrier.

\section{NECK INJURES SIMULATION}

Following motor crash evaluations, a EuroSID-2 adult male dummy were seated on a sled, restrained using belts, and lateral velocity was applied.

The cervical spine muscle force provided postural stability to maintain the neutral posture and passive resistance to intervertebral motion following the side impact, thus approximating the response of an unwarned occupant. Although a driver may be able to foresee the side impact, he may not respond quickly enough to develop sufficient neck muscle force in time to alter the intervertebral kinematics during the impact [4]. Therefore, there was no active force to exert on the joints of C1-C7 vertebrae elements.

Fig. (7) is the dummy body movement after side impact. As we can see from the figures, due to the huge impact energy, the neck sprains and strains are inevitable.

\section{RESULTS ANALYSIS}

The human cervical spinal column is a three dimensional structure, and the ligaments responsible for maintaining functional interrelationships among the various spinal compo- 


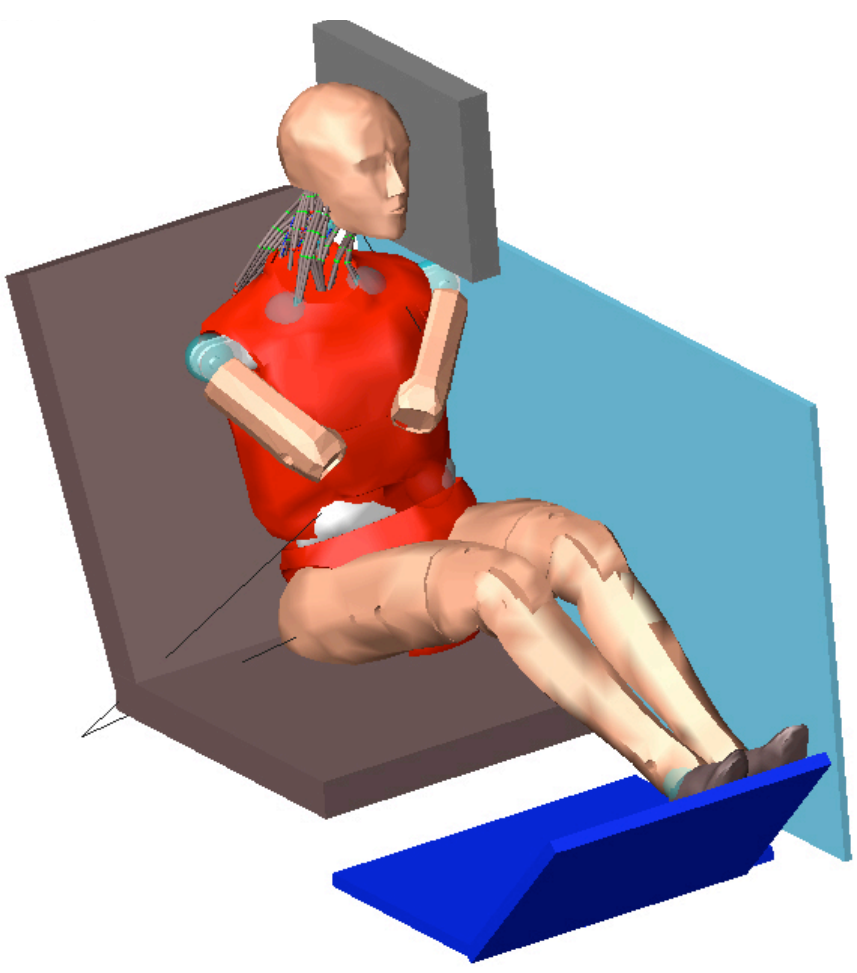

Fig. (7). Dummy body movement after side impact.

nents are complex in geometry and material property. Fig. (8) to Fig. (11) provide an overview of disk bending loads, extension muscle loads, interspinous ligament loads disk shear strain at head-c1, c1-c2, c2-c3, c3-c4, c4-c5, c5-c5, c6c7 and c7-t1.

Compressive forces are transferred through the intervertebral disc, the vertebral body, and the facet joints. The intervertebral disc is a viscoelastic material and its mechanical properties are dependent on the rate of loading. At low load rates the disc deforms and is more flexible, but at higher rates the disk becomes stiff [40].

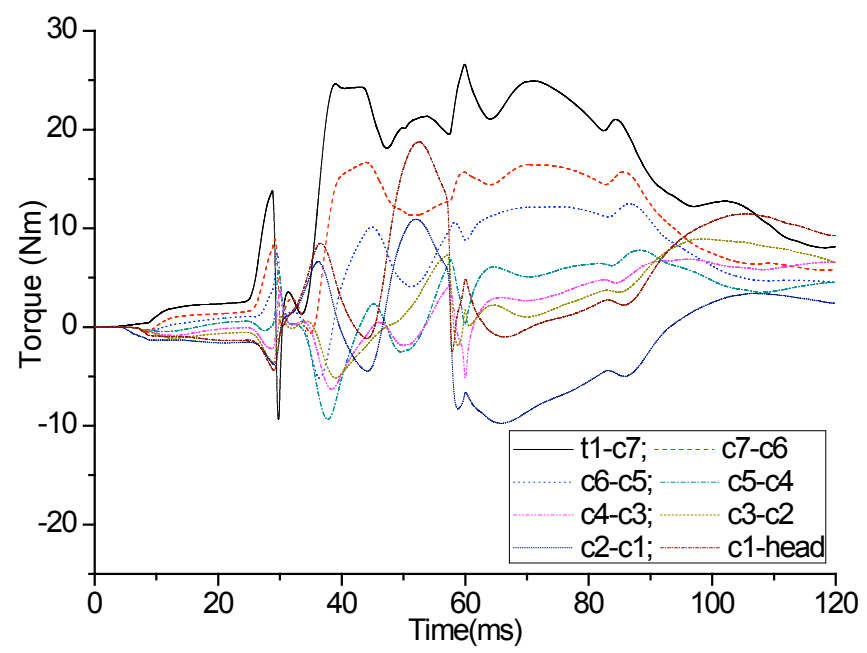

Fig. (8). Disk bending loads.

The results show that bending torque in the discs increases with flexion of the vertebrae and reaches a maximum at all levels at around $48 \mathrm{~ms}$ in conjunction with maximum neck rotation. A peak in anterior shear of the discs at all levels can be seen at around $30 \mathrm{~ms}$. During the whole side impact, the load of the t1-c7 interspinous ligament is predominant, as well as the shear strain force of the t1-c7 disc. Therefore, for a neck injured patient, the $\mathrm{t} 1-\mathrm{c} 7$ of the cervical spine is the important inspection area because it is the most likely to be sprained and strained.

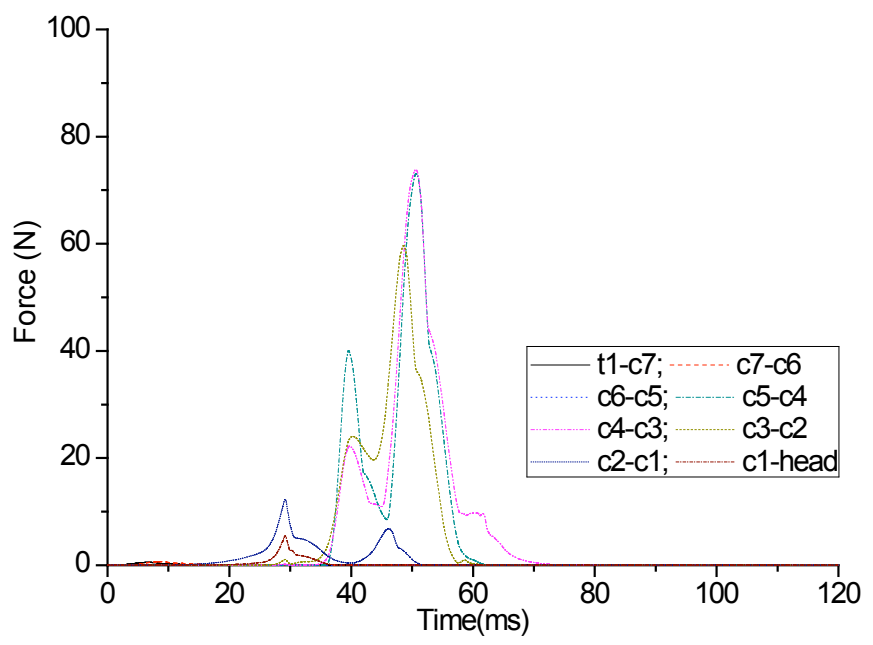

Fig. (9). Interspinous ligament loads.

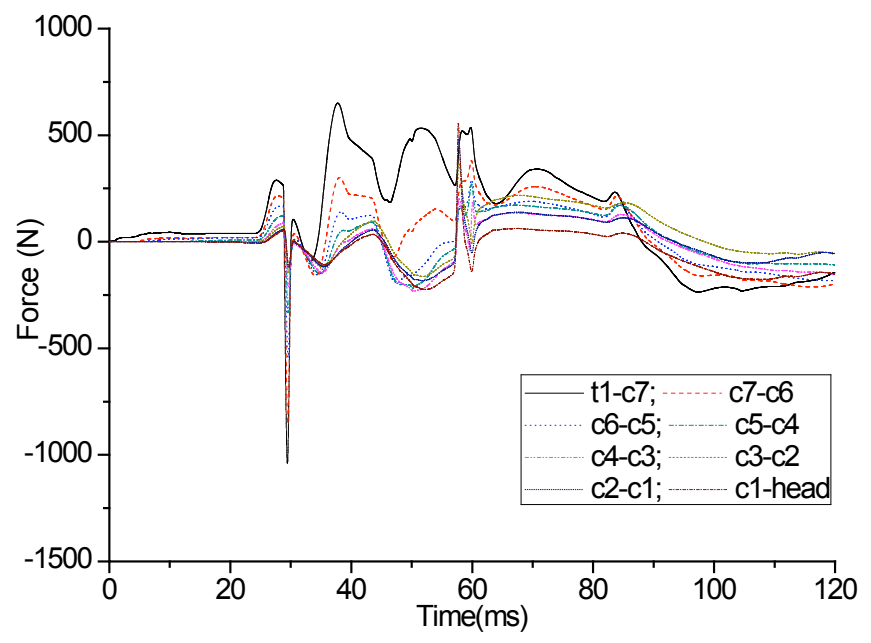

Fig. (10). Disk shear strain for the lateral impact.

c7 and t1 injuries can be classified as either complete or incomplete injuries. Complete injuries result in the total loss of movement and sensation below the point of injury, while incomplete injuries indicate that some function below the level of injury is retained.

Forces and moments causing disc injury increase progressively down the vertebral column. Hiroshi Yamada, Anthony Sances Jr. et al and Bradford Burton et al (and others) found that cervical discs fail at mean loads and moments about $1 / 5$ to $1 / 3$ of lumbar disc values [41]. Since injury thresholds are reduced by up to $1 / 3$ for degenerated discs, the values the $1 / 5$ proportion most likely reflects some degree of disc degeneration.

At more a severe load rate found in higher velocity collisions (44 $\mathrm{J}$ of energy) disc failure occurred at a mean bending moment of $185 \mathrm{Nm}$, and min of $149 \mathrm{Nm}$. 


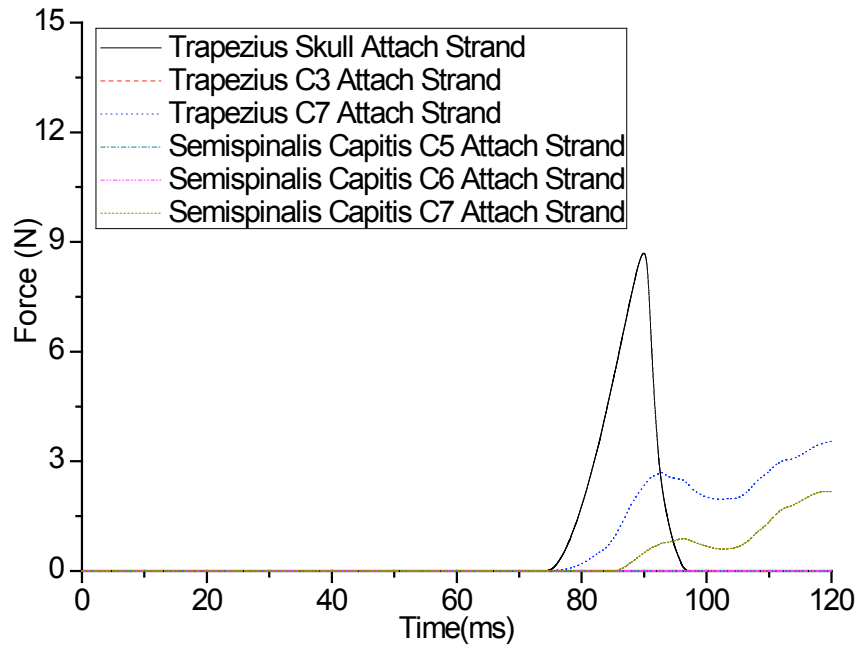

Fig. (11). Extension muscle loads for the lateral impact.

Using the higher $1 / 3$ proportional value, the mean bending moment injury threshold for the cervical region for a somewhat higher speed collision is about $61 \mathrm{Nm}$, and the corresponding minimal threshold value is about $50 \mathrm{Nm}$. (Mean and min at $1 / 5$ proportion is $37 \mathrm{Nm}$ and $30 \mathrm{Nm}$ ).

The disk bending loads maximum at head-c1 and c2-c3 are about $27 \mathrm{Nm}$ and $28 \mathrm{Nm}$ respectively, which are close to the minimal injury threshold value, which means this driver's cervical spine was injured to a certain extent.

The greatest interspinous ligament load tended to occur at $53 \mathrm{~ms}$, with the largest interspinous ligament load observed at c3-c4. Excessive interspinous ligament load may lead to neck sprains and strains.

\section{CONCLUSIONS}

The purpose of this study was to preliminarily evaluate the utility of the multibody approach in cervical spine injuries analysis.

Numerous epidemiologic studies have been completed in the hopes of identifying the cervical spine injury risk patterns that are associated with motor vehicle collisions. Some cervical spine injury may result in a huge economic burden of medical and insurance costs and loss of work force. The mainstay of prevention and treatment of cervical spine injuries is to diagnose exactly in time and maintain good strength and flexibility through conditioning.

This study shows that the methods used in this paper have the potential to provide a costeffective and versatile platform to examine local loadings on the cervical spine and soft tissues, including the kinetics and the kinematics of the cervical spine and its components and the mechanical response of the intervertebral discs under complex dynamic loading environment.

\section{ACKNOWLEDGEMENTS}

This work was supported by the Fundamental Research Funds for the Central Universities (N090403008), the Program for New Century Excellent Talents in University (NCET-08-0103) and the Natural Science Foundation of China (50875041), China.

\section{REFERENCES}

[1] Insurance Research Council, Auto Injury Insurance Claims: Countrywide Patterns in Treatment, Cost, and Compensation, 2008 Edition, Insurance Research Council, Malvern, PA, 2008.

[2] M. J. Van Der Horst, Human Head Neck Response in Frontal, Lateral and Rear End Impact Loading Modelling and Validation, Ph.D. dissertation, Tech. Univ. of Eindhoven, Eindhoven, North Brabant, 2002.

[3] A. M. Pearson, M. M. Panjabi, P. C. Ivancic, S. Ito, B. W. Cunningham, W. Rubin, and S. E. Gimenez, "Frontal impact causes ligamentous cervical spine injury," Spine, vol. 30, no. 16, pp. 1852-1858, 2005.

[4] M. M. Panjabi, A. M. Pearson, S. Ito, P. C. Ivancic, S. E. Gimenez, and Y. Tominaga, "Cervical spine ligament injury during simulated frontal impact”, Spine, vol. 29, no. 21, pp. 2395-2403, 2004.

[5] P. C. Ivancic, A. M. Pearson, Y. Tominaga, A. K. Simpson, J. J. Yue, and M. M. Panjabi, "Mechanism of cervical spinal cord injury during bilateral facet dislocation," Spine, vol. 32, no. 22, pp. $2467-$ 2473, 2007.

[6] V. Esat, D. W. Van Lopik, and M. Acar, "Combined multi-body dynamic and FE models of human head and neck," in Proc. of IUTAM Symp. on Impact Biomechanics, Dublin, 2005, pp. 91-100.

[7] S. Himmetoglu, M. Acar, A. J. Taylor, and K. Bouazza-Marouf, “A multi-body head-and-neck model for simulation of rear impact in cars," Proc. IMechE, Part D: J. Automobile Eng., vol. 221, no. 5, pp. 527-541, 2007.

[8] D. W. Van Lopik, and M. Acar, "A computational model of the human head and neck system for the analysis of whiplash motion," Int. J. Crashworthiness, vol. 9, no. 5, pp. 465-473, 2004.

[9] D. W. Van Lopik and M. Acar, "Development of a multi-body computational model of human head and neck," Proc. IMechE, Part K: J. Multi-body Dyn, vol. 221, no. 2, pp. 175-197, 2007.

[10] D. W. Van Lopik, and M. Acar, "Dynamic verification of a multibody computational model of human head and neck for frontal, lateral, and rear impacts," Proc. IMechE, Part K: J. Multi-body Dyn., vol. 221, no. 2, pp. 199-217, 2007.

[11] A. Veloso, G. Esteves, S. Silva, C. Ferreira, and F. Brandao, "Biomechanics modeling of human musculoskeletal system using Adams multibody dynamics package," in Proc. of the 24th IASTED Int. Conf. on Biomedical Engineering, Innsbruck, 2006, pp. 401407.

[12] S. M. Kim, I. C. Yang, and M. P. Lee, "Cervical spine injury analysis regarding frontal and side impacts of wheelchair occupant in vehicle by LifeMOD," in IFMBE Proc., 2007, vol. 14, no. 4, pp. 2521-2524.

[13] L. X. Guo, M. Zhang, Z. W. Wang, Y. M. Zhang, B. C. Wen, and J. $\mathrm{L}$. Li, "Influence of anteroposterior shifting of trunk mass centroid on vibrational configuration of human spine," Comput. Biol. Med., vol. 38 , no. 1 , pp. 146-151, 2008.

[14] Z. P. Li, J. E. Alonso, J. E. Kim, J. S. Davidson, B. S. Etheridge, and A. W. Eberhardt, "Three-dimensional finite element models of the human pubic symphysis with viscohyperelastic soft tissues," Ann. Biomed. Eng., vol. 34, no. 9, pp. 1452-1462, 2006.

[15] H. Yu, M. B. Medri, Q. Zhou, F. P. DiMasi, and F. A. Bandak, "Head-neck finite element model of the crash test dummy THOR," Int. J. Crashworthiness, vol. 9, no. 2, pp. 175-186, 2004.

[16] P. Tropiano, L. Thollon, P. J. Arnoux, R. C. Huang, K. Kayvantash, D. G. Poitout, and C. Brunet, "Using a finite element model to evaluate human injuries application to the HUMOS model in whiplash situation," Spine, vol. 29, no. 16, pp. 1709-1716, 2004.

[17] E. C. Teo, Q. H. Zhang, and T. X. Qiu, "Finite element analysis of head-neck kinematics under rear-end impact conditions," in Int. Conf. on Biomedical and Pharmaceutical Engineering, Singapore, 2006, pp. 206-209.

[18] E. C. Teo, and H. W. Ng, "First cervical vertebra (atlas) fracture mechanism studies using finite element method," J. Biomech., vol. 34, no. 1, pp. 13-21, 2001.

[19] H. W. Ng, E. C. Teo, and Q. H. Zhang, "Prediction of intersegment stability and osteophyte formation on the multi-segment C2-C7 after unilateral and bilateral facetectomy," Proc. IMechE, Part H: J. Eng. Med., vol. 218, no. 3, pp. 183-191, 2004.

[20] Q. H. Zhang, S. H. Tan, and E. C. Teo, "Finite element analysis of head-neck kinematics under simulated rear impact at different accelerations," Proc. IMechE, Part H: J. Eng. Med, vol. 222, no. 5, pp. 781-790, 2008. 
[21] M. J. Fagan, S. Julian, and A. M. Mohsen, "Finite element analysis in spine research," Proc. IMechE, Part H: J. Eng. Med., vol. 216, no. 5, pp. 281-298, 2002.

[22] W. Z. Golinski, and R. Gentle, "The influence of seat back rake on ligament loadings in rear-end impact," Proc. IMechE, Part D: $J$. Automobile Eng., vol. 219, no. 2, pp. 197-205, 2005.

[23] N. Yoganandan, S. Kumaresan, and F. A. Pintar, "Geometric and mechanical properties of human cervical spine ligaments," $J$ Biomech. Eng., vol. 122, no. 6, pp. 623-629, 2000.

[24] N. Yoganandan, F. A. Pintar, J. Zhang, B. D. Stemper, and M. Philippens, "Upper neck forces and moments and cranial angular accelerations in lateral impact," Ann. Biomed. Eng., vol. 36, no. 3, pp. 406-414, 2008.

[25] N. Yoganandan, F. A. Pintar, D. J. Maiman, M. Philippens, and J. Wismans, "Neck forces and moments and head accelerations in side impact," Traffic Inj. Prev., vol. 10, no. 1, pp. 51-57, 2009.

[26] B. D. Stemper, N. Yoganandan, and F. A. Pintar, "Validation of a head-neck computer model for whiplash simulation," Med. Biol. Eng. Comput., vol. 42, no. 3, pp. 333-338, 2004.

[27] W. Hell, S. Schick, K. Langwieder, and H. Zellmer, "Biomechanics of cervical spine injuries in rear end car impacts: influence of car seats and possible evaluation criteria," Traffic Inj. Prev., vol. 3, no. 2, pp. 127-140, 2002.

[28] J. Latchford, E. C. Chirwa, T. Chen, and M. Mao, "The relationship of seat backrest angle and neck injury in low-velocity rear impacts," Proc. IMechE, Part D: J. Automobile Eng., vol. 219, no. 11, pp. 1293-1302, 2005.

[29] M. M. Panjabi, P. C. Ivancic, Y. Tominaga, and J. L. Wang, "Intervertebral neck injury criterion for prediction of multiplanar cervical spine injury due to side impacts," Traffic Inj. Prev., vol. 6, no. 4, pp. 387-397, 2005.

[30] P. C. Ivancic, S. Ito, M. M. Panjabi, A. M. Pearson, Y. Tominaga, J. L. Wang, and S. E. Gimenez, "Intervertebral neck injury criterion for simulated frontal impacts," Traffic Inj. Prev., vol. 6, no. 2, pp. 175-184, 2005.
[31] M. M. Panjabi, P. C. Ivancic, T. G. Maak, Y. Tominaga, and W. Rubin, "Multiplanar cervical spine injury due to head-turned rear impact," Spine, vol. 31, no. 4, pp. 420-429, 2006.

[32] M. Fukushima, K. Kaneoka, K. Ono, M. Sakane, S. Ujihashi, and N. Ochiai, "Neck injury mechanisms during direct face impact," Spine, vol. 31, no. 8, pp. 903-908, 2006.

[33] J. W. Lee, K. H. Yoon, and G. J. Park, "A study on occupant neck injury in rear end collisions," Proc. IMechE, Part D: J. Automobile Eng., vol. 217, no. 1, pp. 23-29, 2002.

[34] C. R. Gentle, W. Z. Golinski, and F. Heitplatz, "Computational studies of 'whiplash' injuries," Proc. IMechE, Part H: J. Eng. Med., vol. 215, no. 2, pp. 181-189, 2001.

[35] B. S. Zuckerbraun, K. Morrison, B. Gaines, H. R. Ford, and D. J. Hackam, "Effect of age on cervical spine injuries in children after motor vehicle collisions: effectiveness of restraint devices," $J$. Pediatr. Surg., vol. 39, no. 3, pp. 483-486, 2004.

[36] R. K. Wilcox, "The biomechanical effect of vertebroplasty on the adjacent vertebral body: a finite element study," Proc. IMechE, Part H: J. Eng. Med., vol. 220, no. 4, pp. 565-572, 2006.

[37] R. J. Oakland, R. M. Hall, R. K. Wilcox, and D. C. Barton, "The biomechanical response of spinal cord tissue to uniaxial loading," Proc. IMechE, Part H: J. Eng. Med., vol. 220, no. 4, pp. 489-492, 2006.

[38] E. M. K. P. Barros, C. J. Rodrigues, N. R. Rodrigues, R. P. Oliveira, T. E. Barros, and A. J. Rodrigues, "Aging of the elastic and collagen fibers in the human cervical interspinous ligaments," Spine J., vol. 2, no. 1, pp. 57-62, 2002.

[39] P. C. Ivancic, M. P. Coe, A. B. Ndu, Y. Tominaga, E. J. Carlson, W. Rubin, F. H. Dipl-Ing, and M. M. Panjabi, "Dynamic mechanical properties of intact human cervical spine ligaments," Spine J., vol. 7, no. 6, pp. 659-665, 2007.

[40] A. A. White, R. M. Johnson, M. M. Panjabi, and W. O. Southwick, "Biomechanical analysis of clinical stability in the cervical spine," Clin. Orthop. Relat. Res., vol. 109, pp. 85-96, 1975.

[41] H. Yamada, Strength of Biological Materials. Baltimore, MD: Williams and Wilkins, 1970.

Received: September 23, 2010

Revised: October 26, 2010

Accepted: October 26, 2010

(C) Zhou et al.; Licensee Bentham Open.

This is an open access article licensed under the terms of the Creative Commons Attribution Non-Commercial License (http: //creativecommons.org/licenses/by$\mathrm{nc} / 3.0 /$ ), which permits unrestricted, non-commercial use, distribution and reproduction in any medium, provided the work is properly cited. 